\section{JURNAL EKONOMI EFEKTIF}

ISSN : $2622-8882$, E-ISSN : 2622-9935

Jurnal Ekonomi Efektif, Vol. 3, No. 4, Juli 2021

@Prodi Manajemen Fakultas Ekonomi Universitas

Pamulang

\title{
PENGARUH PELATIHAN DAN DISIPLIN KERJA TERHADAP KINERJA KARYAWAN PADA PT. PRATAMA ABADI INDUSTRI DI TANGERANG
}

\author{
Sutrisno $^{1 *}$, Yanurianto ${ }^{2}$, Yossy Wahyu Indrawan ${ }^{3}$ \\ Universitas Pamulang, Tangerang Selatan, Banten, Indonesia \\ dosen00035@unpam.ac.id*
}

Manuskrip: Mei -2021 Ditinjau: Mei -2021; Diterima: Mei-2021; Online: Juli-2021; Diterbitkan: Juli-2021

\begin{abstract}
ABSTRAK
Penelitian ini bertujuan untuk mengetahui pengaruh pelatihan dan disiplin kerja terhadap kinerja karyawan pada PT. Pratama Abadi Industri di Tangerang. Metode yang digunakan adalah explanatory research dengan teknik analisis menggunakan analisis statistik dengan pengujian regresi, korelasi, determinasi dan uji hipotesis. Hasil penelitian ini pelatihan berpengaruh signifikan terhadap kinerja karyawan sebesar 43,7\%, uji hipotesis diperoleh $\mathrm{t}$ hitung $>\mathrm{t}$ tabel atau $(11,981>1,973)$. Disiplin kerja berpengaruh signifikan terhadap kinerja karyawan sebesar 43,1\%, uji hipotesis diperoleh $t$ hitung $>t$ tabel atau $(11,839>1,973)$. Pelatihan dan disiplin kerja secara simultan berpengaruh signifikan terhadap kinerja karyawan dengan persamaan regresi $\mathrm{Y}=10,078+0,423 \mathrm{X} 1+0,427 \mathrm{X} 2$ dan kontribusi pengaruh sebesar $52,2 \%$, uji hipotesis diperoleh $\mathrm{F}$ hitung $>\mathrm{F}$ tabel atau $(100,498>2,680)$.
\end{abstract}

\section{Kata Kunci: Pelatihan, Disiplin Kerja, Kinerja Karyawan}

\section{ABSTRACT}

This study aims to determine the effect of training and work discipline on employee performance at PT. Pratama Abadi Industri in Tangerang. The method used is explanatory research with analytical techniques using statistical analysis with regression, correlation, determination and hypothesis testing. The results of this study that training has a significant effect on employee performance by $43.7 \%$, hypothesis testing is obtained $t$ count $>t$ table or (11,981 > 1,973). Work discipline has a significant effect on employee performance by $43.1 \%$, hypothesis testing is obtained $t$ count $>$ t table or (11,839 > 1,973). Training and work discipline simultaneously have a significant effect on employee performance with the regression equation $Y=10.078+0.423 X 1+0.427 X 2$ and the contribution of the influence is $52.2 \%$, hypothesis testing is obtained $F$ count $>F$ table or $(100,498>2,680)$.

Keywords: Training, Work Discipline, Employee Performance 


\section{PENDAHULUAN}

\section{A. Latar Belakang}

Sumber daya manusia memiliki peranan yang sangat strategis dalam menyelenggarakan dan menjalankan bisnis dalam suatu organisasi. peran karyawan sangat penting karena unsur manusia memegang peranan penting dalam melakukan aktivitas kegiatan perusahaan dan berperan aktif dalam kebijakan dan pencapaian tujuan organisasi. Dengan sumber daya manusia yang handal maka kegiatan operasional perusahaan akan berjalan dengan lancar.

Pemerintah sendiri telah menerbitkan aturan (keputusan Presiden) No.37/2014 yang memuat banyak indikator yang harus dicapai dalam upaya untuk meningkatkan daya saing nasional dan menghadapi MEA yang sudah dimulai 2015 itu. Dengan diterbitkan inpres No.6/2014, tentang peningkatan daya saing menghadapi Masyarakat Ekonomi ASEAN, pemerintah Indonesia sudah menyiapkan pengembangan sektor industri, agar bisa bersaing di pasar bebas ASEAN itu.

Di tengah perhelatan perdagangan bebas, setidaknya Indonesia telah memiliki bekal berupa UU Perdagangan. Suatu organisasi dapat berjalan efektif apabila fungsifungsi manajemen seperti perencanaan (planning), pengorganisasian (organizing), pengarahan (actuating) dan pengendalian (controlling) apabila semua itu berfungsi dengan baik, serta unsur-unsur penunjangnya tersedia dan memenuhi persyaratan maka organisasi akan mampu meningkatkan kinerjanya. Salah satu unsur terpenting yang dapat mendukung jalannya perusahaan adalah sumber daya manusia (pegawai). Tenaga kerja atau sumber daya manusia dapat diartikan sebagai karyawan, pekerja atau pegawai yang memiliki keahlian dibidangnya masing-masing pada hakikatnya mempunyai maksud yang sama untuk mencapai suatu tujuan organisasi atau perusahaan.

Tabel 1. Target Kinerja dan Realisasi Capaian Karyawan PT. Pratama Abadi Industri

Tangerang Selatan Periode Tahun 2017-2019

\begin{tabular}{|c|c|c|c|c|}
\hline Tahun & $\begin{array}{c}\text { Target Kinerja } \\
\text { (Unit Sepatu) }\end{array}$ & $\begin{array}{c}\text { Realisasi Produksi } \\
\text { (Unit) }\end{array}$ & Persentase & Keterangan \\
\hline 2017 & 10000.000 & 9500.000 & $95,0 \%$ & Tidak tercapai \\
\hline 2018 & 10000.000 & 9300.000 & $93,0 \%$ & Tidak tercapai \\
\hline 2019 & 10000.000 & 9250.000 & $92,5 \%$ & Tidak tercapai \\
\hline
\end{tabular}

Sumber: PT. Pratama Abadi Industri, diolah, 2020

Berdasarkan pada data tabel di atas, menunjukan bahwa realisasi produksi berupa hasil produksi sepatu pada tahun 2017 dengan persentase 95,0\% dari target yang ditetapkan. Tahun 2018 dengan persentase 93,0\%. Pada tahun 2019 dengan persentase 92,5\%. Realisasi produksi PT. Pratama Abadi Industri memiliki rata-rata 94\% unit setiap tahun, sedangkan target produksi tiap tahun mengalami kenaikan. Hal ini menunjukan bahwa kinerja karyawan masih terkoreksi karena tidak mencapai target yang di inginkan perusahaan.

Evaluasi kerja merupakan upaya untuk mengetahui kondisi pencapaian kerja sehingga dapat diketahui apakah ada kemajuan dan kendala sehingga dapat dinilai dan dipelajari untuk perbaikan di masa mendatang Disisi lain Evaluasi kinerja merupakan aktivitas analisis sistimatik, pemberian solusi atas masalah yang ditemukan untuk tujuan peningkatan kinerja. Dalam berbagai hal evaluasi dilakukan melalui monitoring terhadap sistim yang ada.namun adakalanya evaluasi tidak dapat dilakukan hanya dengan menggunakan informasiyang dihasilkan oleh sistim informasi yang ada pada unit kerja ,Data dari luar unit kerja juga sangat penting sebagai bahan analisis yang dapat dipakai dalam mengukur kinerja karyawan.

Penurunan pencapaian produksi berdasar pada tabel di atas, disinyalir diasebabkan adanya laryawan yang kurang mendapatkan kesempatan yang proporsional terkait 
dengan pelatihan yang diadakan perusahaan. Untuk meningkatkan kemampuan kerja yang optimal, diperlukan pengelolaan sumber daya manusia yang baik, salah satu cara yang umum dilakukan perusahaan adalah melalui pelatihan. Pelatihan akan memberikan kesempatan karyawan untuk dapat mengembangkan keahlian kemampuan dalam bekerja, dan untuk menambah pengetahuan sehingga karyawan dapat mengerti, memahami, dan menguasai apa yang harus dikerjakan dan mengapa harus dikerjakan, apa yang seharusnya dilakukan dan bagaimana melakukannya. Diharapkan melalui program pelatihan yang sudah dilaksanakan dalam perusahaan akan memberikan dampak positif terhadap peningkatan keahlian, wawasan, pengetahuan, dan perilaku karyawan pada tugas-tugasnya sehingga kinerja karyawan perusahaan tersebut dapat meningkat.

Berikut adalah data pelatihan yang diberikan PT. Pratama Abadi Industri kepada karyawan untuk periode tahun 2014-2018, sebagai berikut:

Tabel 2. Data Jumlah Peserta Pelatihan Karyawan Periode Tahun 2015-2019

\begin{tabular}{|c|c|c|c|c|c|}
\hline \multirow{2}{*}{ Tahun } & Jumlah & \multicolumn{2}{|c|}{ Trained } & \multicolumn{2}{c|}{ Untrained } \\
\cline { 3 - 6 } & Karyawan & Karyawan & $\%$ & Karyawan & $\%$ \\
\hline 2015 & 340 & 85 & $25,00 \%$ & 255 & $75,00 \%$ \\
\hline 2016 & 348 & 90 & $25,86 \%$ & 258 & $74,14 \%$ \\
\hline 2017 & 350 & 91 & $26,00 \%$ & 259 & $74,00 \%$ \\
\hline 2018 & 350 & 90 & $26,57 \%$ & 257 & $73,43 \%$ \\
\hline 2019 & 350 & 85 & $24,29 \%$ & 265 & $75,71 \%$ \\
\hline \multicolumn{2}{|c|}{ Rata-rata } & 88 & $25,54 \%$ & 259 & $74,46 \%$ \\
\hline
\end{tabular}

Sumber: PT. Pratama Abadi Industri, diolah, 2020

Berdasarkan data pada tabel di atas, terlihat bahwa kegiatan pelatihan yang diadakan oleh perusahaan dalam rangka meningkatkan kemampuan karyawan dari tahun 20152019 tidak maksimal, rata-rata hanya 25,54\% yang diberikan kesempatan pelatihan. Sedangkan yang belum diberikan kesempatan untuk mengikuti pelatihan sebesar $74,46 \%$. Kondisi ini juga diikuti dengan meteri dan metode pelatihan yang kurang sesuai dengan kebutuhannya.

Selain pelatihan yang kurang maksimal, penurunan kinerja juga disinyalir dari kurang disiplinnya karyawan dalam bekerja. Disiplin kerja yang tidak berjalan dengan baik akan berdampak pada kemajuan organisasi. Tanpa disiplin yang baik pada karyawan, sulit bagi organisasi untuk mencapai hasil yang optimal. Tindakan tidak disiplin (Indisipliner) akan berdampak pada pertumbuhan organisasi perusahaan. Disiplin dikatakan juga sebagai sarana untuk melatih dan mendidik orang-orang terhadap peraturan-peraturan agar ada kepatuhan dan supaya dapat berjalan dengan tertip dan teratur dalam organisasi. Peraturan perusahaan dibuat tentu bertujuan agar dapat dipatuhi oleh karyawan baik dari ketaatan karyawan dalam menepati waktu bekerja, ketaatan dalam mematuhi semua aturan yang ada dalam perusahaan, ketaatan terkait perilaku karyawan dalam menjalankan tugas dan kewajibannya, ketaatan karyawan dalam menjunjung tinggi norma hukum dan aturan lainnya.

Perusahaan juga penting mensosialisasikan semua ketentuan dan peraturan perusahaan agar dapat dipahami oleh karyawan dan diawasi, dilakukan kontrol dengan baik sehingga tidak terjadi hambatan yang dapat memperlambat tercapainya tujuan perusahaan. Dengan demikian, karyawan dapat melaksanakan tugasnya dengan penuh kesadaran serta dapat mengembangkan tenaga dan pikirannya semaksimal mungkin demi terwujudnya tujuan organisasi. Dari hasil pengumpulan data awal berupa resume pelanggaran karyawan yang dihimpun dari data tahun 2017-2019, sebagai berikut: 
Tabel 3. Data Kedisiplinan Karyawan PT. Pratama Abadi Industri Periode Tahun 20172019

\begin{tabular}{|c|c|c|c|c|c|}
\hline \multirow[t]{2}{*}{ No } & \multirow[t]{2}{*}{ Aspek } & \multirow[t]{2}{*}{ Pokok Aturan } & \multicolumn{3}{|c|}{$\begin{array}{c}\text { Jumlah Pelanggaran } \\
\text { (Karyawan) }\end{array}$} \\
\hline & & & 2017 & 2018 & 2019 \\
\hline \multirow{5}{*}{1} & \multirow{5}{*}{$\begin{array}{c}\text { Taat pada aturan } \\
\text { waktu }\end{array}$} & Jam kerja : 0.800-17.00 & 10 & 15 & 17 \\
\hline & & Jam Istirahat: $12.00-13.00$ & 15 & 20 & 16 \\
\hline & & Lembur & 22 & 20 & 25 \\
\hline & & Cuti & 5 & 8 & 8 \\
\hline & & Meninggalkan pekerjaan & 11 & 14 & 16 \\
\hline \multirow{3}{*}{2} & \multirow{3}{*}{$\begin{array}{c}\text { Taat terhadap } \\
\text { peraturan } \\
\text { perusahaan } \\
\end{array}$} & Seragam kerja & 10 & 9 & 12 \\
\hline & & Tingkah laku dalam pekerjaan & 5 & 3 & 9 \\
\hline & & Meninggalkan pekerjaan & 12 & 15 & 18 \\
\hline \multirow{3}{*}{3} & \multirow{3}{*}{$\begin{array}{c}\text { Taat terhadap } \\
\text { aturan perilaku } \\
\text { dalam pekerjaan }\end{array}$} & Cara melakukan pekerjaan & 3 & 3 & 6 \\
\hline & & Tanggung jawab pekerjaan & 10 & 13 & 17 \\
\hline & & Koordinasi dengan unit lain & 15 & 22 & 24 \\
\hline \multirow{3}{*}{4} & \multirow{3}{*}{$\begin{array}{l}\text { Taat terhadap } \\
\text { norma hukum }\end{array}$} & Ketatasusilaan & - & - & - \\
\hline & & Melawan pemerintah & - & - & - \\
\hline & & Tindak pidana & - & - & - \\
\hline \multirow{5}{*}{5} & \multirow{5}{*}{$\begin{array}{l}\text { Ketaatan terhadap } \\
\text { peraturan lainnya }\end{array}$} & Peralatan kerja & 13 & 15 & 22 \\
\hline & & Perjalanan dinas & - & - & - \\
\hline & & Kesehatan & - & - & - \\
\hline & & Penyelesaian keluh kesah & - & - & - \\
\hline & & Narkoba/obat terlarang/kriminal & - & - & - \\
\hline & & otal & & & \\
\hline
\end{tabular}

Sumber: PT. Pratama Abadi Industri, diolah, 2020

Berdasarkan data tabel di atas, aspek dan pokok aturan yang dibuat perusahaan, masih banyak yang dilanggar oleh karyawan. Aspek ketaatan pada waktu, masih ada karyawan yang datang terlambat dan pulang lebih awal. Pada aspek ketaatan dalam mematuhi peraturan juga kurang dibuktikan dengan masih adanya pelanggaran seragam kerja, demikian pula dengan peraturan lainnya

Berdasarkan latar belakang permasalahan diatas, maka penulis tertarik untuk melakukan penelitian lebih lanjut dengan judul: "Pengaruh Pelatihan dan Disiplin Kerja Terhadap Kinerja Karyawan Pada PT. Pratama Abadi Industri di Tangerang"

\section{B. Rumusan Masalah}

1. Adakah pengaruh pelatihan terhadap kinerja karyawan pada PT. Pratama Abadi Industri di Tangerang ?

2. Adakah pengaruh disiplin kerja terhadap kinerja karyawan pada PT. Pratama Abadi Industri di Tangerang ?

3. Adakah pengaruh secara simultan pelatihan dan disiplin kerja terhadap kinerja karyawan pada PT. Pratama Abadi Industri di Tangerang?

\section{Tujuan Penelitian}

1. Untuk mengetahui pengaruh pelatihan terhadap kinerja karyawan pada PT. Pratama Abadi Industri di Tangerang.

2. Untuk mengetahui pengaruh disiplin kerja terhadap kinerja karyawan pada PT. Pratama Abadi Industri di Tangerang.

3. Untuk mengetahui pengaruh secara simultan antara pelatihan dan disiplin kerja terhadap kinerja karyawan pada PT. Pratama Abadi Industri di Tangerang. 


\section{TINJAUAN PUSTAKA}

\section{Pelatihan}

Yang dimaksud pelatihan dalam penelitian mengacu pada pendapat Veithzal Rivai (2015:240) yang dimaksud pelatihan dalam penelitian ini "Proses secara sistematis mengubah tingkah laku pegawai untuk mencapai tujuan organisasi. Pelatihan berkatian dengan keahlian dan kemampuan pegawai untuk melaksanakan pekerjaan". Adapun indikator yang digunakan dalam penelitian ini meliputi: Materi pelatihan, metode pelatihan, kemampuan instruktur, peserta pelatihan dan evaluasi pelatihan

\section{Disiplin kerja}

Menurut Singodimedjo dalam Sutrisno (2017:86), menyatakan bahwa "Disiplin adalah sikap kesediaan dan kerelaan seseorang untuk mematuhi dan menaati normanorma peraturan yang berlaku disekitarnya.". Pada dasarnya ada banyak indikator yang memepengaruhi tingkat kedisiplinan karyawan suatu organisasi. Namun Edy Sutrisno (2017:86) dispilin kerja dibagi dalam lima dimensi antaranya adalah : Taat terhadap aturan waktu, Taat terhadap peraturan perusahaan, Taat terhadap aturan perilaku dalam pekerjaan, Taat terhadap norma dan aturan hukum, Taat terhadap peraturan lainnya

\section{Kinerja Karyawan}

Dalam penelitian ini variabel terikatnya adalah kinerja karyawan. Yang dimaksud kinerja dalam penelitian mengacu pada pendapat Mangkunegara (2016:75) yaitu hasil kerja secara kualitas dan kuantitas yang dicapai oleh seorang pegawai dalam melaksanakan tugasnya sesuai dengan tanggung jawab yang diberikan kepadanya. Adapun indikator yang digunakan meliputi: 1) Kualitas, 2) kuantitas, 3) pelaksanaan tugas, 4) tanggung jawab pekerjaan.

\section{METODE PENELITIAN}

\section{Populasi}

Populasi dalam penelitian ini berjumlah 187 responden PT. Pratama Abadi Industri di Tangerang

\section{Sampel}

Sampel dalam penelitian ini berjumlah 187 responden.

\section{Jenis Penelitian}

Jenis penelitian yang dipakai adalah kuantitatif, dimana tujuannya adalah untuk mengetahui pengaruh antara variabel bebas terhadap variabel terikat baik parsial maupun simultan

\section{Metode Analisis Data}

Dalam menganalisis data digunakan uji instrumen, uji asumsi klasik, regresi, koefisien korelasi, koefisien determinasi dan uji hipotesis.

\section{HASIL PENELITIAN}

\section{Analisis Deskriptif}

Pada pengujian ini digunakan untuk mengetahui skor minimum dan maksimum, mean score dan standar deviasi dari masing-masing variabel. Adapun hasilnya sebagai berikut:

\begin{tabular}{|c|c|c|c|c|c|}
\hline \multicolumn{6}{|c|}{ Descriptive Statistics } \\
\hline & $\mathrm{N}$ & Minimum & Maximum & Mean & Std. Deviation \\
\hline Pelatihan (X1) & 187 & 29 & 48 & 37.93 & 3.801 \\
\hline Disiplin Kerja (X2) & 187 & 29 & 46 & 37.66 & 3.647 \\
\hline
\end{tabular}




\begin{tabular}{l|l|l|l|l|r}
\hline Kinerja Karyawan (Y) & 187 & 31 & 52 & 42.19 & 3.993 \\
\hline Valid N (listwise) & 187 & & & & \\
\hline
\end{tabular}

Pelatihan diperoleh varians minimum sebesar 29 dan varians maximum 48 dengan mean score sebesar 37,93 dengan standar deviasi 3,801.

Disiplin kerja diperoleh varians minimum sebesar 29 dan varians maximum 46 dengan mean score sebesar 37,66 dengan standar deviasi 3,647.

Kinerja karyawan diperoleh varians minimum sebesar 31 dan varians maximum 52 dengan mean score sebesar 42,19 dengan standar deviasi 3,993.

\section{Analisis Kuantitatif}

Pada analisis ini dimaksudkan untuk mengetahui pengaruh variabel independen terhadap variabel dependen. Adapun hasil pengujian sebagai berikut:

\section{a. Analisis Regresi Linier Berganda}

Uji regresi ini dimaksudkan untuk mengetahui perubahan variabel dependen jika variabel independen mengalami perubahan. Adapun hasil pengujiannya sebagai berikut:

\begin{tabular}{|c|c|c|c|c|c|c|}
\hline \multirow{3}{*}{\multicolumn{2}{|c|}{ Model }} & \multicolumn{3}{|c|}{ Coefficients $^{\mathbf{a}}$} & \multirow[b]{3}{*}{$\mathrm{t}$} & \multirow[b]{3}{*}{ Sig. } \\
\hline & & \multicolumn{2}{|c|}{$\begin{array}{l}\text { Unstandardized } \\
\text { Coefficients }\end{array}$} & \multirow{2}{*}{$\begin{array}{c}\text { Standardized } \\
\text { Coefficients } \\
\text { Beta }\end{array}$} & & \\
\hline & & $\mathrm{B}$ & Std. Error & & & \\
\hline 1 & (Constant) & 10.078 & 2.277 & & 4.427 & .000 \\
\hline & Pelatihan (X1) & .423 & .071 & .403 & 5.920 & .000 \\
\hline & Disiplin Kerja (X2) & .427 & .074 & .390 & 5.726 & .000 \\
\hline
\end{tabular}

a. Dependent Variable: Kinerja Karyawan (Y)

Berdasarkan hasil pengujian pada tabel di atas, diperoleh persamaan regresi $\mathrm{Y}$ $=10,078+0,423 \mathrm{X} 1+0,427 \mathrm{X} 2$. Dari persamaan tersebut dijelaskan sebagai berikut:

1) Konstanta sebesar 10,078 diartikan jika pelatihan dan disiplin kerja tidak ada, maka telah terdapat nilai kinerja karyawan sebesar 10,078 point.

2) Koefisien regresi pelatihan sebesar 0,423 , angka ini positif artinya setiap ada peningkatan pelatihan sebesar 0,423 maka kinerja karyawan juga akan mengalami peningkatan sebesar 0,423 point.

3) Koefisien regresi disiplin kerja sebesar 0,427 , angka ini positif artinya setiap ada peningkatan disiplin kerja sebesar 0,427 maka kinerja karyawan juga akan mengalami peningkatan sebesar 0,427 point.

\section{b. Analisis Koefisien Korelasi}

Analisis koefisien korelasi dimaksudkan untuk mengetahui tingkt kekuatan hubungan dari variabel independen terhadap variabel dependen baik secara parsial maupun simultan. Adapun hasil pengujian sebagai berikut:

Tabel 6. Hasil Pengujian Koefisien Korelasi Pelatihan Terhadap Kinerja

Karyawan.

Correlations $^{b}$

\begin{tabular}{llr|r} 
& & Kinerja Karyawan \\
& & Pelatihan $(\mathrm{X} 1)$ & \multicolumn{2}{c}{$(\mathrm{Y})$} \\
\hline Pelatihan (X1) & Pearson Correlation & 1 & $.661^{* *}$ \\
\cline { 2 - 4 } & Sig. (2-tailed) & & .000 \\
\hline Kinerja Karyawan (Y) & Pearson Correlation & $.661^{* *}$ & 1 \\
\cline { 2 - 4 } & Sig. (2-tailed) & .000 & \\
\hline
\end{tabular}

**. Correlation is significant at the 0.01 level (2-tailed).

b. Listwise $\mathrm{N}=187$

Berdasarkan hasil pengujian diperoleh nilai korelasi sebesar 0,661 artinya 
pelatihan memiliki hubungan yang kuat terhadap kinerja karyawan.

Tabel 7. Hasil Pengujian Koefisien Korelasi Disiplin kerja Terhadap Kinerja

$$
\begin{aligned}
& \text { Karyawan } \\
& \text { Correlations }^{\mathbf{b}}
\end{aligned}
$$

\begin{tabular}{llr|r} 
& & $\begin{array}{c}\text { Disiplin Kerja } \\
(\mathrm{X} 2)\end{array}$ & $\begin{array}{r}\text { Kinerja Karyawan } \\
(\mathrm{Y})\end{array}$ \\
\hline Disiplin Kerja (X2) & Pearson Correlation & 1 & $.657^{* *}$ \\
\cline { 2 - 4 } & Sig. (2-tailed) & & .000 \\
\hline Kinerja Karyawan (Y) & Pearson Correlation & $.657^{* *}$ & 1 \\
\cline { 2 - 4 } & Sig. (2-tailed) & .000 & \\
\hline
\end{tabular}

**. Correlation is significant at the 0.01 level (2-tailed).

b. Listwise $\mathrm{N}=187$

Berdasarkan hasil pengujian diperoleh nilai korelasi sebesar 0,657 artinya disiplin kerja memiliki hubungan yang kuat terhadap kinerja karyawan.

Tabel 8. Hasil Pengujian Koefisien Korelasi Pelatihan dan Disiplin kerja secara simultan Terhadap Kinerja Karyawan

\begin{tabular}{l|c|cr|rr} 
& & \multicolumn{2}{c}{ Model Summary } \\
Model & $\mathrm{R}$ & R Square & $\begin{array}{c}\text { Adjusted R } \\
\text { Square }\end{array}$ & \multicolumn{2}{c}{$\begin{array}{c}\text { Std. Error of the } \\
\text { Estimate }\end{array}$} \\
\hline 1 & $.723^{\mathrm{a}}$ & .522 & .517 & 2.775 \\
\hline
\end{tabular}

a. Predictors: (Constant), Disiplin Kerja (X2), Pelatihan (X1)

Berdasarkan hasil pengujian diperoleh nilai korelasi sebesar 0,723 artinya pelatihan dan disiplin kerja secara simultan memiliki hubungan yang kuat terhadap kinerja karyawan.

\section{c. Analisis Koefisien Determinasi}

Analisis koefisien determinasi dimaksudkan untuk mengetahui besarnya persentase pengaruh dari variabel independen terhadap variabel dependen baik secara parsial maupun simultan. Adapun hasil pengujian sebagai berikut:

\begin{tabular}{|c|c|c|c|c|}
\hline \multicolumn{5}{|c|}{$\begin{array}{c}\text { Karyawan } \\
\text { Model Summary }\end{array}$} \\
\hline Model & $\mathrm{R}$ & R Square & $\begin{array}{l}\text { Adjusted R } \\
\text { Square }\end{array}$ & $\begin{array}{l}\text { Std. Error of the } \\
\text { Estimate }\end{array}$ \\
\hline 1 & $.661^{\mathrm{a}}$ & .437 & 434 & 3.004 \\
\hline
\end{tabular}

Tabel 9. Hasil Pengujian Koefisien Determinasi Pelatihan Terhadap Kinerja

a. Predictors: (Constant), Pelatihan (X1)

Berdasarkan hasil pengujian diperoleh nilai determinasi sebesar 0,437 artinya pelatihan memiliki kontribusi pengaruh sebesar 43,7\% terhadap kinerja karyawan.

Tabel 10. Hasil Pengujian Koefisien Determinasi Disiplin kerja Terhadap

Kinerja Karyawan

\begin{tabular}{|c|c|c|c|c|}
\hline \multicolumn{5}{|c|}{ Model Summary } \\
\hline Model & $\mathrm{R}$ & R Square & $\begin{array}{l}\text { Adjusted R } \\
\text { Square }\end{array}$ & $\begin{array}{l}\text { Std. Error of the } \\
\text { Estimate }\end{array}$ \\
\hline 1 & $.657^{\mathrm{a}}$ & .431 & .428 & 3.020 \\
\hline
\end{tabular}

Model Summary

Berdasarkan hasil pengujian diperoleh nilai determinasi sebesar 0,431 artinya disiplin kerja memiliki kontribusi pengaruh sebesar 43,1\% terhadap kinerja karyawan. 
Tabel 11. Hasil Pengujian Koefisien Determinasi Pelatihan dan Disiplin kerja Terhadap Kinerja Karyawan Model Summary

\begin{tabular}{|c|c|c|c|c|}
\hline \multicolumn{5}{|c|}{ Model Summary } \\
\hline Model & $\mathrm{R}$ & R Square & $\begin{array}{l}\text { Adjusted R } \\
\text { Square }\end{array}$ & $\begin{array}{l}\text { Std. Error of the } \\
\text { Estimate }\end{array}$ \\
\hline 1 & $.723^{\mathrm{a}}$ & .522 & .517 & 2.775 \\
\hline
\end{tabular}

a. Predictors: (Constant), Disiplin Kerja (X2), Pelatihan (X1)

Berdasarkan hasil pengujian diperoleh nilai determinasi sebesar 0,522 artinya pelatihan dan disiplin kerja secara simultan memiliki kontribusi pengaruh sebesar $52,2 \%$ terhadap kinerja karyawan, sedangkan sisanya sebesar 47,8\% dipengaruhi faktor lain.

\section{d. Uji Hipotesis}

Uji hipotesis Parsial (Uji t)

Pengujian hipotesis dengan uji t digunakan untuk mengetahui hipotesis parsial mana yang diterima.

Hipotesis pertama: Terdapat pengaruh yang signifikan antara pelatihan terhadap kinerja karyawan.

Tabel 12. Hasil Uji Hipotesis Pelatihan Terhadap Kinerja Karyawan

\begin{tabular}{|c|c|c|c|c|c|c|}
\hline \multirow{3}{*}{\multicolumn{2}{|c|}{ Model }} & \multicolumn{3}{|c|}{ Coefficients $^{a}$} & \multirow[b]{3}{*}{$\mathrm{t}$} & \multirow[b]{3}{*}{ Sig. } \\
\hline & & \multicolumn{2}{|c|}{$\begin{array}{l}\text { Unstandardized } \\
\text { Coefficients }\end{array}$} & \multirow{2}{*}{$\begin{array}{c}\text { Standardized } \\
\text { Coefficients } \\
\text { Beta }\end{array}$} & & \\
\hline & & $\mathrm{B}$ & Std. Error & & & \\
\hline 1 & (Constant) & 15.859 & 2.209 & & 7.180 & .000 \\
\hline & Pelatihan (X1) & .694 & .058 & .661 & 11.981 & .000 \\
\hline
\end{tabular}

a. Dependent Variable: Kinerja Karyawan $(\mathrm{Y})$

Berdasarkan hasil pengujian pada tabel di atas, diperoleh nilai t hitung $>\mathrm{t}$ tabel atau $(11,981>1,973)$, dengan demikian hipotesis pertama yang diajukan bahwa terdapat pengaruh yang signifikan atara pelatihan terhadap kinerja karyawan diterima.

Tabel 13. Hasil Uji Hipotesis Disiplin kerja Terhadap Kinerja Karyawan

\begin{tabular}{|c|c|c|c|c|c|c|}
\hline \multirow[b]{2}{*}{ Model } & & $\begin{array}{l}\text { Unstar } \\
\text { Coe }\end{array}$ & $\begin{array}{l}\text { dardized } \\
\text { icients }\end{array}$ & $\begin{array}{l}\text { Standardized } \\
\text { Coefficients }\end{array}$ & \multirow[b]{2}{*}{6} & \multirow[b]{2}{*}{ Sig. } \\
\hline & & B & Std. Error & Beta & & \\
\hline 1 & (Constant) & 15.121 & 2.297 & & 6.582 & .000 \\
\hline & Disiplin Kerja (X2) & .719 & .061 & .657 & 11.839 & .000 \\
\hline
\end{tabular}

a. Dependent Variable: Kinerja Karyawan $(\mathrm{Y})$

Berdasarkan hasil pengujian pada tabel di atas, diperoleh nilai t hitung $>\mathrm{t}$ tabel atau $(11,839>1,973)$, dengan demikian hipotesis kedua yang diajukan bahwa terdapat pengaruh yang signifikan atara disiplin kerja terhadap kinerja karyawan diterima.

\section{Uji Hipotesis Simultan (Uji F)}

Pengujian hipotesis dengan uji $\mathrm{F}$ digunakan untuk mengetahui hipotesis simultan yang mana yang diterima.

Hipotesis ketiga Terdapat pengaruh yang signifikan antara pelatihan dan disiplin kerja terhadap kinerja karyawan. 
Tabel 14. Hasil Uji Hipotesis Pelatihan dan Disiplin kerja Terhadap Kinerja Karyawan.

\begin{tabular}{|c|c|c|c|c|c|c|}
\hline \multicolumn{7}{|c|}{$\begin{array}{c}\text { Karyawan. } \\
\text { ANOVAa }^{\text {NNOA }}\end{array}$} \\
\hline \multicolumn{2}{|c|}{ Model } & Sum of Squares & df & Mean Square & $F$ & Sig. \\
\hline \multirow[t]{3}{*}{1} & Regression & 1547.982 & 2 & 773.991 & 100.498 & $.000^{\mathrm{b}}$ \\
\hline & Residual & 1417.088 & 184 & 7.702 & & \\
\hline & Total & 2965.070 & 186 & & & \\
\hline
\end{tabular}

a. Dependent Variable: Kinerja Karyawan (Y)

b. Predictors: (Constant), Disiplin Kerja (X2), Pelatihan (X1)

Berdasarkan hasil pengujian pada tabel di atas, diperoleh nilai $\mathrm{F}$ hitung $>\mathrm{F}$ tabel atau $(100,498>2,680)$, dengan demikian hipotesis ketiga yang diajukan bahwa terdapat pengaruh yang signifikan atara pelatihan dan disiplin kerja terhadap kinerja karyawan diterima.

\section{Pembahasan Hasil Penelitian}

\section{Pengaruh Pelatihan Terhadap Kinerja Karyawan}

Pelatihan berpengaruh signifikan terhadap kinerja karyawan dengan korelasi sebesar 0,661 atau memiliki hubungan yang kuat dengan kontribusi pengaruh sebesar 43,7\%. Pengujian hipotesis diperoleh nilai $t$ hitung $>\mathrm{t}$ tabel atau $(11,981>1,973)$. Dengan demikian hipotesis pertama yang diajukan bahwa terdapat berpengaruh signifikan antara pelatihan terhadap kinerja karyawan diterima.

\section{Pengaruh Disiplin kerja Terhadap Kinerja Karyawan}

Disiplin kerja berpengaruh signifikan terhadap kinerja karyawan dengan korelasi sebesar 0,657 atau memiliki hubungan yang kuat dengan kontribusi pengaruh sebesar $43,1 \%$. Pengujian hipotesis diperoleh nilai $t$ hitung $>\mathrm{t}$ tabel atau $(11,839>1,973)$. Dengan demikian hipotesis kedua yang diajukan bahwa terdapat berpengaruh signifikan antara disiplin kerja terhadap kinerja karyawan diterima.

\section{Pengaruh Pelatihan dan Disiplin kerja Terhadap Kinerja Karyawan}

Pelatihan dan disiplin kerja berpengaruh signifikan terhadap kinerja karyawan dengan diperoleh persamaan regresi $\mathrm{Y}=10,078+0,423 \mathrm{X} 1+0,427 \mathrm{X} 2$, nilai korelasi sebesar 0,723 atau memiliki hubungan yang kuat dengan kontribusi pengaruh sebesar $52,2 \%$ sedangkan sisanya sebesar $47,8 \%$ dipengaruhi faktor lain. Pengujian hipotesis diperoleh nilai $\mathrm{F}$ hitung $>\mathrm{F}$ tabel atau $(100,498>2,680)$. Dengan demikian hipotesis ketiga yang diajukan bahwa terdapat berpengaruh signifikan antara pelatihan dan disiplin kerja terhadap kinerja karyawan diterima.

\section{KESIMPULAN DAN SARAN}

\section{Kesimpulan}

a. Pelatihan berpengaruh signifikan terhadap kinerja karyawan dengan kontribusi pengaruh sebesar 43,7\%. Uji hipotesis diperoleh nilai thitung $>\mathrm{t}$ tabel atau $(11,981>$ 1,973).

b. Disiplin kerja berpengaruh signifikan terhadap kinerja karyawan dengan kontribusi pengaruh sebesar 43,1\%. Uji hipotesis diperoleh nilai t hitung $>t$ tabel atau $(11,839>$ 1,973).

c. Pelatihan dan disiplin kerja berpengaruh signifikan terhadap kinerja karyawan dengan kontribusi pengaruh sebesar 52,2\% sedangkan sisanya sebesar $47,8 \%$ dipengaruhi faktor lain. Uji hipotesis diperoleh nilai $F$ hitung > F tabel atau $(100,498>2,680)$. 


\section{Saran}

a. Perusahaan harus selektif dalam melakukan program pelatihan karyawan agar mampu secara tepat pelatihan yang dilaksanakan benar-benar sesuai dengan kebutuhan karyawan dalam rangka menunjang pekerjaannya.

b. Perusahaan harus memberikan bimbingan dan penyuluhan bagi karyawan dalam menciptakan tata tertib yang baik di perusahaan serta pemberian sanksi yang sepadan. Dengan tata tertib yang baik, semangat kerja, moral kerja,

c. Kinerja perusahaan dapat ditingkatkan dengan memberdayakan karyawan dengan menegakkan peraturan yang baik dan pemberian disiplin kerja yang lebih inten lagi.

\section{DAFTAR PUSTAKA}

Algifari (2015). Analisis Regresi untuk Bisnis dan Ekonomi. Yogyakarta: BPFE.

Anwar Prabu Mangkunegara, "Manajemen Sumber Daya Manusia Perusahaan". Remaja Rosdakarya. Bandung, 2015.

Carrel, Michael R., Elbert, Norbert F., Hatfield, Robert D., "Human Resource. Management: Global Strategies for Managing a Diverse Workplace", 2015

Danang Sunyoto, "Metodologi Penelitian Akuntansi". PT Refika Aditama, Bandung, 2016 Edwin B Flippo, "Prinsip-Prinsip Sumber Daya Manusia", Edisi ke Duabelas, Erlangga, Jakarta, 2014.

Edy Sutrisno "Sumber Daya Manusia”, PT. Gramedia, Surabaya, 2016.

Eli Yulinti, Jurnal Administrasi Bisnis, 2015, 3 (4): ISSN: 2355-5408, Pengaruh Pelatihan Terhadap Kinerja Karyawan Setelah diadakan pelatihan pada Karyawan Grand Fatma Hotel di Tenggarong.

G.R. Terry, and Rue, Leslie W. Rue, "Dasar-dasar Manajemen”, Bumi Aksara, Jakarta 2015.

Garry Dessler, "Human Resources Management", Prenticehall, International Inc, London, 2013.

Ghozali "Aplikasi Analisis Multivariate dengan Program SPSS", Edisi Kelima, Badan Penerbit Undip, Semarang, 2016

Gitosudarmo Indriyo. "Manajemen" Edisi kedua, cetakan kedua. Penerbit : BPFE Yogyakarta, 2013.

Gomes, Faustino Cardoso. 2003. Manajemen Sumber Daya Manusia. Jakarta: Andi Offset, 2014

Handoko, "Manajemen Personalia dan Sumberdaya Manusia", Edisi Kelima, BPFE UGM, Yogyakarta, 2012.

Hasibuan, SP, “Dasar-dasar Perbankan”, Haji Masagung, Jakarta, 2016.

Hermawati, R., Sugiyarti, L., Handayani, R., Sunarsi, D., Alfiah, S., \& Maddinsyah, A. (2020). The Effect of Trilogy Leadership Style and Organization Culture on School Performance: Evidence form Indonesian Senior High School. PalArch's Journal of Archaeology of Egypt/Egyptology, 17(6), 8512-8537.

Husein Umar, "Metode Penelitian Untuk Skripsi Dan Tesis Bisnis". PT. Rajawali Pers, Jakarta, 2015

I Ardana, I Komang dkk. "Manajemen Sumber Daya Manusia”. Graha Ilmu, Yogyakarta, 2012.

Imam Ghozali (2017). Aplikasi Analisis Multivariate Dengan Program SPSS. Edisi Kelima. Semarang: Badan Penerbit Undip.

Istijanto (2014) Riset Sumber Daya Manusia. Jakarta: PT. Gramedia Pustaka

Johanes Eliezer Ayer, Lyndon, Pangemanan dan Yolanda P.I. Rori, Jurnal Agri Sosio Ekonomi Unsrat, Vol. 12 Nomor 3A (2016), ISSN : 1907-4298. Pengaruh Motivasi 
dan Disiplin Kerja Terhadap Kinerja Pegawai Pada Dinas Pertanian Kabupaten Supiori

John R. Schermerhorn, Jr, "Manajemen”, edisi kelima, Andi, Yogyakarta, 2013

Keith Davis dan William B. Wether "Perilaku Dalam Organisasi" Jilid I, Terjemahan Agus Dharma, Erlangga, Jakarta, 2014.

Meilawati, D., Rawi, R. D. P., Lewenussa, R., \& Bintari, W. C. (2019). Pengaruh Pemberian Insentif Terhadap Kinerja Karyawan Pada Pt Telesindoshop Kota Sorong. Manajemen Dewantara, 3(1), 128-137

Miftah Thoha "Kepemimpinan Dalam Manajemen”, Edisi Pertama, PT. Raja Grafindo, Jakarta, 2016.

Nurjaya, N., Affandi, A., Ilham, D., Jasmani, J., \& Sunarsi, D. (2021). Pengaruh Kompetensi Sumber Daya Manusia Dan Kemampuan Pemanfaatan Teknologi Terhadap Kinerja Aparatur Desa Pada Kantor Kepala Desa Di Kabupaten Gunungkidul, Yogyakarta. JENIUS (Jurnal Ilmiah Manajemen Sumber Daya Manusia), 4(3), 332-346.

Robbins, S. \& Judge, T, “Organizational Behavior”, Edisi keduabelas,, Prentice Hall, 2014.

Sedarmayanti. "Manajemen Sumber Daya Manusia, Reformasi Birokrasi dan Manajemen Pegawai Negeri Sipil”, Cetakan Kelima, PT Refika Aditama, Bandung, 2016.

Singgih Santoso (2015). Menguasai Statistik Multivariat. Jakarta: PT Elex Media Komputindo.

Siregar, Syofian, “Metode Penelitian Kuantitatif”. PT Fajar Interpratama Mandiri, Jakarta, 2015

Sudjana, "Metode Statistika", Edisi Keenam, Tarsito, Bandung, 2011.

Sugiyono (2017), Metode Penelitian Administrasi : dilengkapi dengan Metode R \& D, Bandung: Alfabeta.

Suharsimi Arikunto "Prosedur Penelitian Suatu Pendekatan Praktek", PT. Rineka Cipta, Jakarta, 2015.

Sutrisno, S. (2018). Pengaruh Pelatihan Pelayanan Prima Dan Disiplin Kerja Terhadap Kinerja Karyawan Pada PT. Sumber Sarana. JENIUS (Jurnal Ilmiah Manajemen Sumber Daya Manusia), 2(1).

Sutrisno, S. (2019). Pengaruh Kepemimpinan Dan Disiplin Kerja Terhadap Kinerja Guru SMP Muhammadiyah 44 Pamulang. JENIUS (Jurnal Ilmiah Manajemen Sumber Daya Manusia), 3(1), 58-73.

Syofian Siregar, "Statistika Deskriptif Untuk Penelitian", PT Raja Grafindo Persada, Jakarta, 2015.

Thoha, Miftah, "Perilaku Organisasi, Konsep Dasar dan Aplikasinya", Raja Grafindo Persada, Jakarta. 2015

Veithzal Rivai, , "Manajemen Sumber Daya Manusia Untuk Perusahaan”, Raja Grafindo Persada, Jakarta, 2015.

Wilandari, D. F., Sunarsi, D., \& Mas'adi, M. (2021). Pengaruh Penilaian Kerja Terhadap Kinerja Karyawan Pada PT. Jaya Mandiri Rekabuana di Cilandak. Jurnal Ekonomi Efektif, 3(2). 